\title{
A face desperta: um passeio pela obra de Wagner Vieira
}

\author{
Cristiane Vilhena Lima ${ }^{1}$ \\ Dulce Mary Godinho Pereira²
}

Resenha de livro: VIEIRA, Wagner José. Enquanto dorme a sua face. Conselheiro Lafaiete: Liga Ecológica Santa Matilde, 2021, 96p.

Wagner Vieira, autor do livro Enquanto dorme a sua face, é um poeta, editor e educador social nascido na antiga Real Vila de Queluz, hoje Conselheiro Lafaiete. Conselheiro Lafaiete é a terra de origem da ONG Liga Ecológica Santa Matilde LESMA, coletivo do qual Wagner Vieira é integrante e atual presidente, e que foi fundado pelo poeta, publicitário e educador Osmir Camilo Gomes. A LESMA, além de possuir uma significativa produção com várias publicações, realiza diferentes ações culturais, entre elas o Abril Poético e a Lesma Editores, que publica obras de autoras e autores da região do Alto Paraopeba e Vale do Piranga ${ }^{3}$.

A LESMA (Liga Ecológica Santa Matilde) foi fundada em 15 de novembro de 1998 no bairro Santa Matilde, com a intenção de ser um "lugar" de produção que fomentasse e produzisse elementos (atos, seminários, eventos, pesquisas e escritos científicos e literários, projetos, oficinas, poemas) que articulassem construções artísticas e culturais à temática do meio ambiente e, principalmente, à História Regional. Para tanto, além da organização e composição dos poemas para publicação, no mesmo ano de sua fundação foi criado o Jornal da Lesma - que hoje possui mais de 35 edições. Posteriormente, foram fundados: o recital Lesma Poesia (em 2001); a biblioteca Nilo Eustáquio Soares; a Lesma Editores (2006) e o Abril Poético (2006) que acontece todo ano ininterruptamente até os dias atuais.

Este último, o Abril Poético, é um evento desenvolvido pelo grupo LESMA que viaja - no mês de abril de cada ano, e por várias cidades - construindo recitais e

\footnotetext{
${ }^{1}$ Especialista em TV, Cinema e Mídias Digitais. Jornalista. Minas Gerais, Brasil. crisvilhelima@yahoo.com.br; Orcid: https://orcid.org/0000-0002-6729-1020.

${ }^{2}$ Mestra em Teoria da Literatura. Minas Gerais, Brasil. dwlcemary@gmail.com. Orcid: https://orcid.org/0000-0001-8237-3940.

${ }^{3}$ Alto Paraopeba: Cristiano Ottoni, Queluzito, Congonhas, Ouro Branco, Belo Vale, Jeceaba, Entre Rios e Conselheiro Lafaiete. Alto Piranga: Itaverava, Catas Altas da Noruega, Lamim, Piranga, Senhora de Oliveira, Rio Espera, Capela Nova, Caranaiba e Santana dos Montes.
} 
estabelecendo amizades e intercâmbios com outros grupos de poesias e artistas locais em um itinerário que "reconstitui" as trajetórias por Minas Gerais de mineiras e mineiros ilustres. O Abril Poético passa pelas cidades do Alto Paraopeba e Vale do Piranga, pelas cidades de Ouro Preto, Belo Horizonte, e São João del Rei, bem como por algumas cidades do Sul de Minas Gerais. Nos últimos cinco anos o Abril Poético ultrapassou as fronteias das Alterosas, sendo realizado nos estados do Rio de Janeiro, Santa Catarina e Rio Grande do Norte.

Se além do Abril Poético e dos recitais, a LESMA escreveu e publicou diversos livros ${ }^{4}$, o poeta Wagner Vieira, que colaborou na construção e publicação de diferentes obras integrando o grupo, publicou individualmente - nunca sozinho e sempre pela Lesma Editores - o livro Fransciscantos (2013) e o recente Enquanto Dorme a Sua Face (2021).

Sobre o encontro com o livro Enquanto Dorme a Sua Face, vale destacar que ler uma obra sempre é uma observação singular, uma vez que as experiências leitoras envolvem além de procedimentos corriqueiros de leitura, como interpretação, analogias, ressignificações; uma outra sensação: empatia sobre a vivência. Tal termo fora pensado a partir da obra supracitada de Wagner Vieira, que inaugura poemas que tratam, de maneira inovadora, uma partilha e empatia sobre situações vividas, reverenciadas, analisadas em forma de poesia. Ser coautor, a relevante definição para todos os leitores, não é tarefa simplória diante aos temas propostos no livro.

O poema, que dá nome ao título da obra, traz nele um ponto de umbanda cânticos ritualísticos, muitas vezes, acompanhado por percussão de atabaques, - e que provoca os seguintes questionamentos: o que acontece quando o espírito se desprende do corpo? Enquanto dorme a face, o que resta fora o descanso material da carcaça

\footnotetext{
${ }^{4}$ Além do Abril Poético e dos recitais, a LESMA escreveu e publicou os livros "Conselheiro" (livro de poemas que inclui CD musical, ano de 2006), "Patrimônio Histórico, Roteiro Sentimental" (livro/DVD sobre o patrimônio das regiões do Alto Paraopeba e Vale do Piranga no ano de 2008), O amor visto da Ponte (livro de poemas, ano de 2009), "Árvore da Vida", (livro de poemas com CD gravado no ano de 2011) "Geraldo Lucindo Fé, sonho e trabalho" (2016), "Escrevendo Sonhos" (antologia dos alunos da escola municipal Doriol Beato - Conselheiro Lafaiete - 2006); "De Villa Real de Queluz a Conselheiro Lafaiete" (de Antônio Perdigão - 2007); "Lafayette Rodrigues Pereira, um ilustre queluzense" (de Allex Milagre, em duas edições 2009 e 2015); "Poemas de um homem apaixonado" (de Ailton José da Silva Santana dos Montes/MG - 2009); "Família Apolinário, Memória \& Cidadania" (2010); "Química de Nós" (poemas de Afonso Celso Henriques - 2011); "Lavra \& Palavra", (poemas de Camilo de Ávila - 2011), Cinepoesia (Osmir Camilo , 2014); e Fransciscantos (Wagner Vieira, 2014), entre outros. Atualmente a Lesma Editores possui em seu catálogo 35 publicações. O escritor Osmir Camilo, um dos fundadores do grupo, além do Cinepoesia, possui publicados os seguintes livros: Irmandade - 1983, Tempo Metálico 1984, Flor do Mal - 1985, Taturana - 1986, Poemas Informais - 1992, Poesia não Canta em Vão I, II e III - 1996, Melão com Lia - 1998
} 
humana? O ponto de umbanda aparece no último poema da obra, quando já se lê, num passeio sinestésico dos diversos semblantes do sagrado, assim como referências religiosas, como: "semana santa", fé, passagens do Alcorão, "O bezerro de ouro", pecados, entre outros.

O livro é dividido em três partes: "Nevoeiro", "Poeira", "Luzeiro". O primeiro, reúne poemas que, assim como à névoa do não-relevar, muito mais preciso do que o esconder, a névoa que causa um mistério sedutor, há textos que tratam sobre a criação do homem/mulher e da natureza; deusa; consagração de dogmas; santificação e, até mesmo, sobre os segredos da vida. Em todas as divisões de capítulos e, perante todo o livro, há diálogos com outras vozes poéticas -escritores-, que partilham suas impressões sobre os textos de Vieira, promovendo, dessa forma, um intercâmbio entre muitas impressões sobre a literatura do autor. Entre eles: Osmir Gomes, Luiz C.de Paulo, Marcio Hudson, Gustavo Valin, Ana Gusmão, Thais Pereira, além das ilustrações de Ryana G. de Oliveira. Todas estas intercessões assumem um diálogo provocante durante a leitura.

Em "Poeira", segunda parte, assim como algo que encobre a superfície, redefinido o espaço e marcando uma posição temporal, a sequência de textos deste capítulo, tratam, mais uma vez o mistério, mas também, situações pueris; esquecimento; essência da criação da natureza e estátuas de ouro; indagações sobre o mundo; devoção; mito; formação ética e social.

E, por fim, em "Luzeiro", há, então, uma claridade que parece definir melhor o caminho ou ofertar uma esperança para indagações existenciais, mas, talvez, o luzeiro ilumine apenas uma parte das reflexões, uma vez que, neste capítulo, ainda há mais a destrinchar na poética de Vieira. São de conteúdo dessa esfera, portanto: harmonias; ilusões e sonhos; felicidade e tormento; amor; lucidez; palavras densas; lições, entre outros. Em todos os segmentos, há um poema-epígrafe similar para conduzir a leitura, separado em cinco mistérios e modificados apenas, a partir da trajetória a qual os temas assim a seguirá: "No primeiro mistério contemplamos (...)/ No segundo mistério caminhamos (...)No terceiro mistério perdemos (...)/ No quarto mistério choramos(...)/ No quinto mistério partimos(...).

Assim como disse Roland Barthes que era necessário "levantar a cabeça" para ler, é conveniente uma "conversa" com as escolhas do autor, com seus textos e toda a 
sua harmonia ao compor, uma vez que há muitas introduções ou intertextualidades presentes. Identifica-se intertexto com Manuel Bandeira, no poema narrativo "Flash": “café com pão! Café com pão..."; em Carlos Drummond de Andrade, na alusão com o "A perda no caminho"; verbetes e músicas de outras esferas religiosas; autores estrangeiros, como Walt Whitman, Jalal ud-Din Mohammed Rumi e László Krasznahorkai; presença de aldravias - poesia composta por seis linhas poéticas, com palavras de grande densidade emotiva-, aliteração e sinestesia, além da oralidade/coloquialidade e dos neologismos.

A introdução de oximoros marca alguns poemas, principalmente porque tal figura de linguagem exprime uma contradição típica da existência humana ("coração duro/tem medo/e confiança"). Assim como todo ofício do poeta "é brincar com as palavras", como já escrevera José Paulo Paes, este recurso nos textos de Vieira, é de uma criação bastante atraente de sons/significados: "Amar leva tempo/e o tempo/leva.”(...) “alma na palma da mão”, entre outros.

Há, também, a existência de frases populares, coexistindo entre reflexões cotidianas e profundas. Esta marcação traduz uma identificação e representatividade poética. A poesia é para todos, sua compreensão deve ser algo acessível e, por isso, deslumbra-se em composições, como: "pernas para o ar" (...)/ “doido de pedra/sem eira nem beira” (...)/ "parafuso a menos”(...)/ "no mundo da lua”(...) / "É como dar com os/burros n'água"(...), entre outros. À vista disso, o coloquialismo presente na obra é verificado nos mecanismos linguísticos, como pontuação, estabelecendo mais uma forma de leitura atraente ao leitor, numa conversa íntima e solidária: “(...)em contagotas/pedaços de ...ah!”. e “quatrocensnoventa”.

Este modelar-palavras exige não apenas a licença poética, mas um sentimento que vai além do que a Literatura, propriamente, aceita. Seria, então, uma espécie de sentimento sobre grafemas, sons, significados e significantes. Em "De sol a só", lê-se: “(...) como se a licença/poética pudesse/ nos esconder/ do alcance/dos olhos/fechados.

Há forma de composição que se assemelham às expectativas da poesia concreta, quando nota-se um apanhado visual para o entendimento ou contemplação. Logo, verifica-se na proximidade de poemas que tratam, de maneira paralela, situações próximas ou distantes, como no poema "A corda", em que notas musicais fazem comunhão com os versos e estrofes, assim como no texto "O segundo segundo" quando 
o mesmo recurso se faz presente, porém, subtraindo a estrofe da nota musical "LÁ", que permanece vazia, demonstrando, talvez, a falta de harmonia entre sons, notas, cordas, palavras e poesia-vida. Igualmente, há criações de espaço e letras, como em "PS!U", quando o ponto de exclamação, nada mais é do que a letra "i" de cabeça para baixo; além de uma estrofe, também, de cabeça para baixo e invertida, em um processo único de modelagem das letras: (é a vida que me rói/e não tem/meu-pé-me-dói)

O espaçamento entre as letras e poemas é considerado mais uma maneira para expressão de simbologias que vão além do vocábulo, fonemas e significados. Poemas "Ele e Élio" e "Ele e L." estão lado a lado, em folhas próximas, estabelecendo relações, assim como "Alfa," e "Beto" que, embora, sejam dois textos, há grande diálogo entre ambos, em um processo de complemento. A divisão da palavra "desmaiando", "orifício" no poema "Paz, Ciência", define maior expressividade e entonação na leitura, logo, nesta coautoria tão marcante na obra vieirense.

E, por fim, os neologismos "desaparência"; "ilusolhos"; "Liverdade" reservam à composição poética a maior soberania do autor; indagando nestas escolhas, uma forma especial de alcançar a plenitude e encantamento das letras. A experiência dessas passagens, assim como toda a leitura dos versos da obra, ressignificam, de maneira madura e espontânea, o cotidiano. Por isso, a citada empatia sobre a vivência seja a marca singular da poesia, sobretudo, a de Wagner Vieira. 